\title{
The Systematic Features and Self-organizing Attribute of University Industry Collaborative Innovation
}

\author{
Fang Yuan ${ }^{a^{*}}$ and Wei Jiang ${ }^{b}$ \\ Fundamental Science on Radioactive Geology and Exploration Technology Laboratory, East China \\ University of Technology, Nanchang, Jiangxi, China \\ afyuan@ecit.cn, bjw186@163.com
}

Keywords: Collaborative; Innovation; Self-Organizing

\begin{abstract}
This paper analyzed the systematic features and self-organizing attribute of the cooperative innovation system of university industry. It introduced self-organization attribute of university industry cooperative innovation. It proposed some problem in industry university research institution cooperative innovation and prospected the definition of the innovation system of industry university research institution cooperative innovation. The research has an important theoretical and practical significance to provide effective plans for the government, universities, research institutions and enterprises related departments.
\end{abstract}

\section{Introduction}

The collaborative innovation system of university industry is born under the background of the current market economy.Its existence is the necessity for the development of market economy.It is an important system with the purpose to solve the development of science and technology and the transformation of the productivity. System self-organizing theory is to study the formation and the development mechanism of the complex self-organizing system.Its research object is mainly the formation and development mechanism of complex self-organizing system problem,namely under certain conditions, it is the theory about how the system work automatically from disorderly to orderly, and orderly by low-level to senior orderly.The collaborative innovation system of collaborative meets the basic requirements of the self- organizing theory.

\section{The Level Definition of the Collaborative Innovation System of University Industry}

The main level of the system consists mainly of enterprises, educational institutions and government.

The enterprise plays an important role in the collaborative innovation system of university industry, and turns the achievements of science and technology into productive forces.Enterprise must implement ahead in the market change,and to obtain commercial success through absorbing talents,science and technology innovation, system and management optimization,seizing market opportunities, and to realize the survival and profitability of the enterprise finally.

Enterprises as the subsystem of the collaborative innovation system of university industry, mainly consists of three parts:product development, product production and product sale. Product research and development of some of the most important is the science and technology talent,but for enterprise,talented person's investment has some risks in common. The value and the cycle of technology innovation must be took into consideration for business.Enterprises generally lack of product research and development ability, research and development ability of tend to research and development ability is insufficient, and finally losses, even can make the enterprise bankruptcy.So how to reduce the innovation cost of enterprise is an important step in enterprise development. In the production of products, due to different production capacity of enterprises, at the same time the advantages and disadvantages of different products, the cause and doping, the value of the product and the price is not unified,market competition pressure, only through timely product updates, guarantee the advantage of its own products to avoid the occurrence of these problems. The sale of product presents the product value, and the timely optimization of product sales is the key to the market competition. So whether it's product development, product production, product sales, technological innovation is the key [1-3]. 
The institute is the lifeblood of the collaborative innovation system in the university industry, and master the important responsibility of technological innovation. For enterprises, study institutes focus on technological innovation, so it is more specialized in high-tech and technical specialization than the enterprise. The research institutes are composed mainly of institutions of higher learning and research institutes and the technical talents and scientific knowledge are the components of the institutions of learning. Because research institutions focus on technical innovation, often because its technical efficiency is not high, most of the technology cannot be converted into productivity. However, its technical innovation ability is strong, technological innovation speed is more and more fast, higher professional technology, can achieve efficient technology innovation, ensure that the height of the technology leading. It is an important outlet for the academic institution to realize the transformation of science and technology into productivity through the innovation system.

The government is a part of the innovation system, and the laws and regulations introduced by the government often drive the development of the system. At the same time, the government's decision is also the important factor that causes the system to move away from equilibrium.

Government consists of two parts, first is to formulate laws and regulations and norms of national government functional departments, through the optimization of the market economy laws and regulations when beyond its capacity, it can cause the system balanced development, at the same time, by enacting system, can be pushed to the industrial optimization and industrial revolution. In addition, the government can ensure the relative stability of the market through controlling the macroeconomic regulation, guarantee the industry in a relatively stable market environment can be developed rapidly. Second, the government is the nature of the service; the government often plays the lead role in the infrastructure and other related industries and high-tech innovation the dominance of the industry, by adjusting the control of the development of these industries to clean under the market economy, the blindness of industry.

The system object layer consists mainly of knowledge innovation, institutional innovation, technological innovation, market innovation and organizational innovation.In the cooperative innovation system of university industry, the object often subject and state the nature of reaction, and research institutions focuses on knowledge innovation and technological innovation, the government focuses on system innovation and organizational innovation, however,the enterprise focuses on market innovation and product innovation.Due to the interaction and interaction between the subsystems, the rapid development of the cooperative innovation system of university industry is guaranteed.

The system support system is mainly influenced by the policy legal environment. Support system is the support system for the simple external environment and internal environment factors, its essence is both market and government by changing things the development direction and development status, by means of policy or market, adjusting the market supply and demand, maintaining the market running state.

\section{The Systematic Characteristics of Cooperative Innovation in the University Industry}

The enterprises and institutions of study and research play an important role in the cooperative innovation system of university industry, and research institutions is the main force of technological innovation, it holds a lot of new and high technology, and has a steady stream of technical innovation strength and technical innovation talents, and provide a steady stream of power for technological innovation,science and technical progress. And enterprises in the system is laden with responsibility for production and sales, only through constant technical innovation, can stand in the flow of the market, at the same time more transform technology into productivity, enterprise innovation through the industry-university-institute cooperation system can be better, more convenient and effective to choose their own advantages of science and technology into productivity, reduce the cost and time, can timely grasp the trend of the development of the market, timely implement the promotion of 
product ,technological innovation, model optimization, etc. Therefore, the integration of enterprises and research institutions is the producer of technology transformation and technology play a role of subjectivity in the cooperative innovation system of the production and learning research [4-6].

Government is the internal environment of cooperative innovation system of control, as well as system upgrading catalysts, for the innovation system integration plays a dominant role in the development. Government generally control the basic construction industry and the advanced technology industry, it can prompt the direction of technical development, control the flow of talent, and lead the whole of the transformation and development of an industry, at the same time, the laws and decisions of the government is able to dominate the recession, because of the role of this factor,the government in manufacture-learning-research cooperation innovation plays a leading role in the system.

The market is ever-changing, at the same time also is the embodiment of the producers and consumers of supply and demand, it can fully play to the role of the resources, to guide industry development, encourage enterprise technology innovation to improve its market competitiveness. The role of the market on the function and the role of the government there is a certain similarity, but the market can have the effect of bigger and better under the control, and when the government is out of control in market regulation, to be able to adjust the control within the scope of the market control, and then let the market to adjust the role. So the market has a guiding role [7].

The cooperative innovation system of university industry is give full play to the enterprise innovation system, and research institutions and the role of government,more closely combines the function and mutual influence between each other.It can strengthen the objective role of the enterprises and research institutions through the industry-university-institute cooperation system,take the market as the guidance,combined with a variety of means of government, to achieve the optimal allocation of technical direction and technology innovation, improve the market competitiveness of enterprises at the same time,feedback on production-study-research cooperative innovation system. So to strengthen the interaction and help to effectively reduce the cost in the process of technology transfer, shorten the cycle of conversion, and to achieve complementary advantages and risk-sharing, mutually beneficial win-win.

\section{The Systematic Self-Organizing Attribute of the Cooperative Innovation of University Industry}

The cooperative innovation system of university industry has four properties. The first is an open system, system and external system of material, energy and information exchange, the system itself is independent from the external environment. The second is to move away from equilibrium, the system is not in equilibrium, and the system is constantly developing away from equilibrium. The second is to move away from equilibrium, the system is not in equilibrium, and the system is constantly developing away from equilibrium. The fourth is the fluctuation, fluctuation and nonlinear system is far from equilibrium effect of dominance, and the fluctuation is derived from the internal system of complex factors, cause a fluctuation of the amount of one or a few, thus affect the system.

The cooperative innovation system of university industry exists in the market, the system needs to understand the demand of the market, to provide the corresponding technology and products, at the same time system need to accept the test of the market,at the same time in the technology development and production of need exchange of material between system and external system. Therefore, the innovation system is an open system [8].

Because the cooperative innovation system of university industry differences within each subsystem, resources and personnel configuration is not balanced, and between technology and technology, or product and product between good and bad,and people management skills and management experience the phenomenon such as difference,often lead to system existence difference, system far from equilibrium.

Because of the internal influence factors, the development of research cooperation innovation system is a non-linear state. At the same time within the system between various subsystems of technology innovation is a non-linear state, also lead to the instability of the system, due to internal system there are a lot of the influence of nonlinear factors, the nonlinear effects of the external environment of the system at the same time, bring presents the state of the nonlinear system. 
Fluctuation is the dominant force that keeps the system away from equilibrium state. System under the influence of several factors present a different intensity of reaction, some reactions are weak, but some reaction is very strong, but regardless of the impact of weak or strong influence can have a fluctuation phenomenon of system, the system is in a state of relative balance is broken, when the system balance is broken, because the system is to balance the development of itself, makes the system by a state of balance as another kind of balanced development.

\section{Summary}

System consists of the enterprise, government and research institutions of three most.They realize the technology innovation and technological transformation through internal communication in the cooperative innovation system of the production and learning research. Within the system environment, cooperative innovation system will be developed to a stable state, at the same time the government through its own functions and powers, to grasp the operation and direction of the market.Systems and external environments also interact, and parts of the system can operate in a complex, external environment.

The cooperative innovation system of the production and learning research is an open system, combined with the market perspective, the system need to exchange information, to market by understanding the direction of the market and development trend, determine the direction of the technology innovation,develop and upgrade the product through obtaining market feedback and product information and people's requirements. The system takes the raw materials of the product through the market, produces the product in combination with technological innovation, and then sells it to the market. Besides that can draw lessons from other parts of the system development industry-university-institute cooperation innovation system model, prompting, innovation system to better integration of internal innovation system, other systems or industry-university-institute cooperation with things over time, space, the influence of factors such as system is far from equilibrium state to another state of balance development. These factors cause the system to fluctuate, thus activating the system's nonlinear function. The development of the innovation system of the production and research and research cooperation system is constantly improving.

\section{Acknowledgements}

The soft science research project of Jiangxi province (20151BBA10053) and college of humanities and social science research projects in Jiangxi province (GL1507) and technology research project of Jiangxi education department (GJJ151534) (GJJ151543) and Jiangxi education planning project (15YB041) and open fund of fundamental science on radioactive geology and exploration technology laboratory (No. RGET1511) supported this work.

\section{References}

[1] S. Nolfi, Behavior as a complex adaptive system: On the role of self-organization in the development of individual and collective behavior. Complexes. 3(2005) 195-203.

[2] C.Fuchs, W. Hofkirchner, Self-organization, knowledge and responsibility. Kybernetes, 2 (2005) 241-260.

[3] R.C. Calia, FM Guerrini, GL Moura, Innovation networks: From technological development to business model reconfiguration. Technovation. 8 (2007) 426-432.

[4] J. Markard, B. Truffer, Technological innovation systems and the multi-level perspective: Towards an integrated framework. Research Policy. 4 (2008) 596-615.

[5] A. Bergek, S. Jacobsson, B Carlsson, S Lindmark, Analyzing the functional dynamics of technological innovation systems: A scheme of analysis. Research Policy. 3 (2008)407-429.

[6] O.N. Boldov, Innovation dynamics and financial markets in developed countries from a self-organization perspective. Studies on Russian Economic Development. 5(2008)523-530. 
[7] DANG Xing-hua, ZHENG Deng-pan, The Self-organization Evolution Model of Modular Technology Innovation Network. R\& D MANAGEMENT. 4 (2009)54-59.

[8] Ma Fei-hong, University-Industry-Government Cooperative Innovation System Modeling and Simulation Method Research. Computer Simulation. 9 (2012) 1-5. 